\title{
A Role for Sox2 in the Adult Cerebellum
}

\section{Nikolaos Panagiotis Mandalos ${ }^{1,2}$, loannis Karampelas ${ }^{3}$, Marannia Saridaki ${ }^{2}$, Ronald D G McKay ${ }^{5}$, Mark L Cohen ${ }^{4}$ and Eumorphia Remboutsika ${ }^{1,2,5 *}$}

${ }^{1}$ National and Kapodistrian University of Athens, School of Medicine, Department of Pediatrics, Athens, Greece ${ }^{2}$ Stem Cell Biology Laboratory, Biomedical Sciences Research Centre "Alexander Fleming", Vari-Attica, Greece

${ }^{3}$ Department of Neurosurgery, University Hospitals Case Medical Center, Cleveland, OH, USA

${ }^{4}$ Department of Pathology, University Hospitals of Cleveland, Case Western Reserve School of Medicine, Cleveland, OH, USA

${ }^{5}$ The Lieber Institute for Brain Development, Basic Sciences Division, Johns Hopkins Medical Campus, Baltimore, USA

\begin{abstract}
The cerebellum, a derivative of the hindbrain, plays a crucial role in balance and posture as well as in higher cognitive and locomotive processes. Cerebellar development is initiated during the segmental phase of hindbrain formation. Here, we describe the phenotype, of a single surviving adult conditional mouse mutant mouse, in which Sox2 function is ablated in embryonic radial glial cells by means of hGFAP-CRE. The single Sox2 ${ }^{\text {RGINV/mosaic }}$ adult mutant mouse displays motor disability, microsomia, reduced Central Nervous System (CNS) size and cerebellar defects associated with human genetically related congenital abnormalities.
\end{abstract}

Keywords: Neural stem cells; Neural progenitor cells; Neurogenesis; Development; Differentiation; Neurodegeneration; Sox genes

\section{Introduction}

In adult mouse the cerebellum is located dorsally to the brainstem. It plays a fundamental role in sensory-motor processing, exemplifying a well-defined and distinctive neurophysiological structure [1]. The cerebellar cortex is constituted of three layers, spatially designated as the innermost layer- a) the granule cell layer, b) the middle Purkinje cell layer and c) the outmost molecular layer. The outer molecular layer is mainly composed of the axons of granule cells and dendrites of Purkinje cells. The Purkinje single cell layer sets the border between the granule and molecular layers, while the inhibitory Purkinje cells are located between excitatory granule cells and the subpial molecular layer [2]. The complex structure of the cerebellum is well reserved among mammals and birds, budding from the neural tube at early stages of development. The morphogen Fibroblast Growth Factor Eight (Fgf8) signalling pathway is believed to play a crucial role for the setting of the axial boundaries of the cerebellar anlage [3]. In a similar mode, Otx2 has a fundamental role in determining its forebrain and midbrain boundaries [4,5], while Hoxa2 establishes the caudal limits of the cerebellum during embryonic differentiation $[6,7]$.

The pluripotency transcription factor Sox 2 governs the neural lineage commitment during cerebral development, since it controls the proliferation and differentiation of Neural Progenitor Cells (NPCs) [8]. Interestingly, Sox 2 spatially and functionally defines stem cell niches of the mammalian adult cerebrum $[9,10]$. It has also been reported to be expressed in a variety of differentiated cerebellar glia cells in mouse embryogenesis, such as Bergmann glial cells, a radial glia subtype that plays a crucial role in the migration of the cerebellar Purkinje cells and granule cells [11]. Along with Sox1 and Sox9 [12], Sox2 has a consistent expression in the cerebellar Purkinje cell layer in adulthood [13].

We have previously used a Sox $2^{\text {CoIN }}$ conditional mutant mouse to understand how Sox2 governs neural stem and progenitor cell fate during embryogenesis $[7,10,14,15]$. Expression of Sox 2 along with Sox 1 and Sox 9 was detected at the mRNA level in both foetal and adult mouse cerebellar samples, suggesting that the maintenance of these markers in adult tissue is also observed in the human cerebellum. These markers were further confirmed at the protein level on human tissue sections, as Sox 1 , Sox 2 and Sox 9 expression was detected in the Purkinje cell layer of the adult cerebellum. Here we report the behavioural and pathoanatomical defects of a single case conditional Sox 2 adult mutant mouse in radial glia cells. Sox $2^{\text {RGINV/mosaic }}$ adult mouse shows microsomia, motor defects, impaired CNS development and malformations of cerebellar granular and molecular cell layers.

\section{Case Study}

In an effort to understand the role of Sox 2 in neural stem and progenitor cells, we have conditionally ablated the function of Sox 2 in radial glial cells via Sox ${ }^{2 \mathrm{COIN} / \mathrm{COIN}}$ [7], to transgenic $\mathrm{Tg}$ (hGFAPCRE) mouse intercrosses $[7,14,16]$. Tg(hGFAP-CRE) mice express CRE recombinase at embryonic day E13.5 in radial glial cells at dorsal and middle regions of the telencephalon, while at an early birth stage, hGFAP is ubiquously expressed throughout the CNS, in all neural cell types derived from radial glial cells. In adult mice, hGFAP expression is mainly restricted in astrocytes of the brain, and also on neuronal niches, such as the external granule cell layer of the cerebellum, the olfactory bulb, the hippocampal area and the subventricular zone [17]. After performing Sox $2^{\text {COIN/COIN }}$ to Sox $2^{\text {RGINV/+}}$; $\mathrm{Tg}$ (hGFAP-CRE) intercrosses, we observed that adult heterozygote Sox $2^{\text {RGINV/+ TghGFAP- }}$ ${ }^{\mathrm{CRE}}$ offspring appear normal and fertile compared with wild type mice. However, Sox $2^{\text {RGINV/mosaic }} \mathrm{Tg}$ (hGFAP-CRE) mutants, hereafter referred

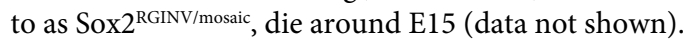

Interestingly though, a single Sox $2^{\text {RGINV/mosaic }}$ mutant escaped embryonic lethality and it developed severe microsomia phenotype evident at the age of 28 postpartum days (Figure 1 (A)). Microsomia was accompanied by severe neurological disorders, as repetitive and stereotyped circular movements, hyperactivity, impaired motor skills

*Corresponding author: Eumorphia Remboutsika, National and Kapodistrian University of Athens, School of Medicine, Department of Pediatrics, Athens, Greece, Tel: 00306974706252; E-mail: remboutsika@gmail.com / eremboutsika@med.uoa.gr/erembou1@jhu.edu

Received June 30, 2018; Accepted July 24, 2018; Published July 27, 2018

Citation: Mandalos NP, Karampelas I, Saridaki M, McKay RDG, Cohen ML, et al (2018) A Role for Sox2 in the Adult Cerebellum. Stem Cell Res Ther 8: 433. doi: 10.4172/2157-7633.1000433

Copyright: (c) 2018 Mandalos NP, et al. This is an open-access article distributed under the terms of the Creative Commons Attribution License, which permits unrestricted use, distribution, and reproduction in any medium, provided the original author and source are credited. 
Citation: Mandalos NP, Karampelas I, Saridaki M, McKay RDG, Cohen ML, et al. (2018) A Role for Sox2 in the Adult Cerebellum. Stem Cell Res Ther 8: 433. doi: 10.4172/2157-7633.1000433

Page 2 of 4

(Figure 2), tremors and lack of appetite, grabbing defects, uncontrolled movements indicating intense stress, phenotypes that are related to brain abnormalities in mouse models with Autistic Spectrum Disorder (ASD), and that have been associated to cerebellar disruptions during development [18].

After observing this pathological phenotype, we opted to focus on the pathoanatomical traits of the cerebellum of this mouse Sox $2^{\mathrm{RGINV} /}$ mosaic mutant, while littermates used as control mice in this study are referred as Sox $2^{\mathrm{RGINV} /+}$. PCR genotyping was performed for both case study Sox $2^{\text {RGINV/mosaic }}$ and its Sox ${ }^{2 \mathrm{RGINV} /+}$ littermates (Figure 1 (B)). Performing dissection of the CNS of the Sox $2^{\text {RGINV/mosaic }}$ mouse, we observed substantially smaller size of the CNS, comparing with its Sox $2^{\text {RGINV/+ }}$ littermate. A substantial number of brain structures such as the olfactory bulb, the cerebellar cortex and the cerebellum were
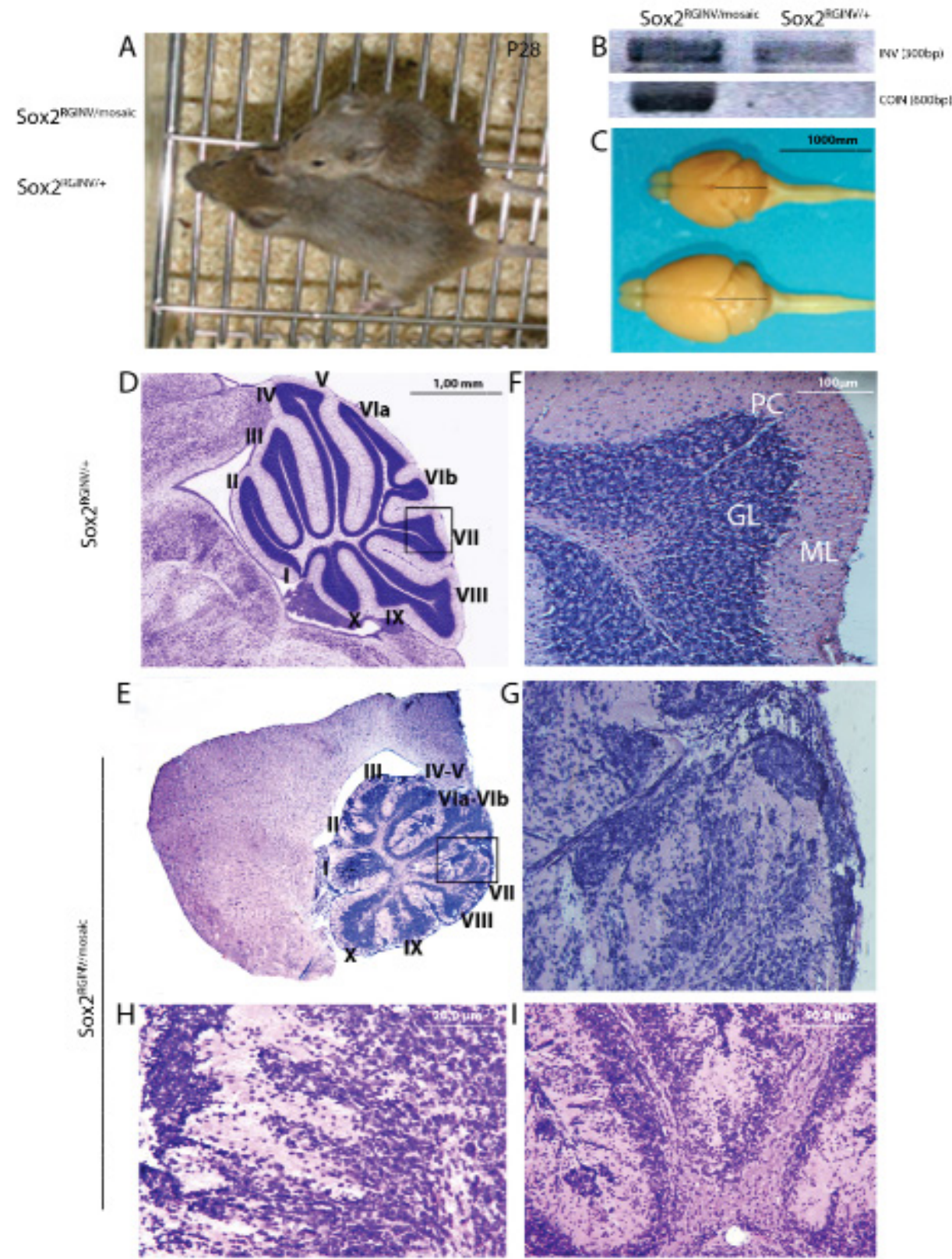

Figure 1: (A) Histolocal Sox2 ${ }^{\text {CoIn/coln }}$ female with hGFAP:CRE male intercrosses yielded a single adult conditional Sox2 ${ }^{\text {RGINV/mosaic }}$ mutant mouse (P28) developing

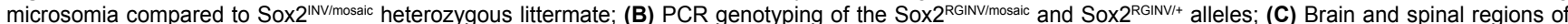
Sox $2^{\mathrm{RGINV} /+}$ (bottom) and Sox2 ${ }^{\mathrm{RGINV} / m o s a i c}$ (top) mutants. Brain and cerebellum size is dramatically reduced as highlighted by the lines in the middle of the vermis (around 30\%); (D, E) Hematoxylin and eosin staining of mid-sagittal sections of the cerebellum of Sox ${ }^{\mathrm{RGINV} /+}$ (D) and Sox2 ${ }^{\mathrm{RGINV} / \mathrm{mosaic}}$ mice (E) Cerebellar lobules are indicated by Roman numerals; $(\mathbf{F}, \mathbf{G})$ Representative sections depicting reduced size and malformed cerebellar fissures at lobule VII of Sox2 ${ }^{\text {RGINV/mosaic }}(\mathbf{G})$ mutant

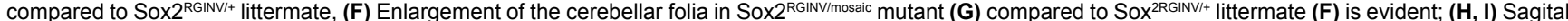

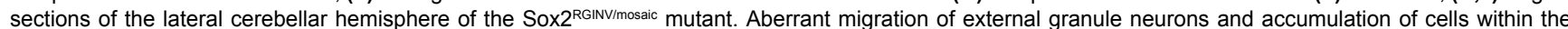
molecular layer and subpial regions of the cerebellar folium are evident. (I) The sulcal depths of the cerebellum of the Sox ${ }^{\text {RGINV/mosaic }}$ mutant depict excess granule neurons in cerebellar white matter. 

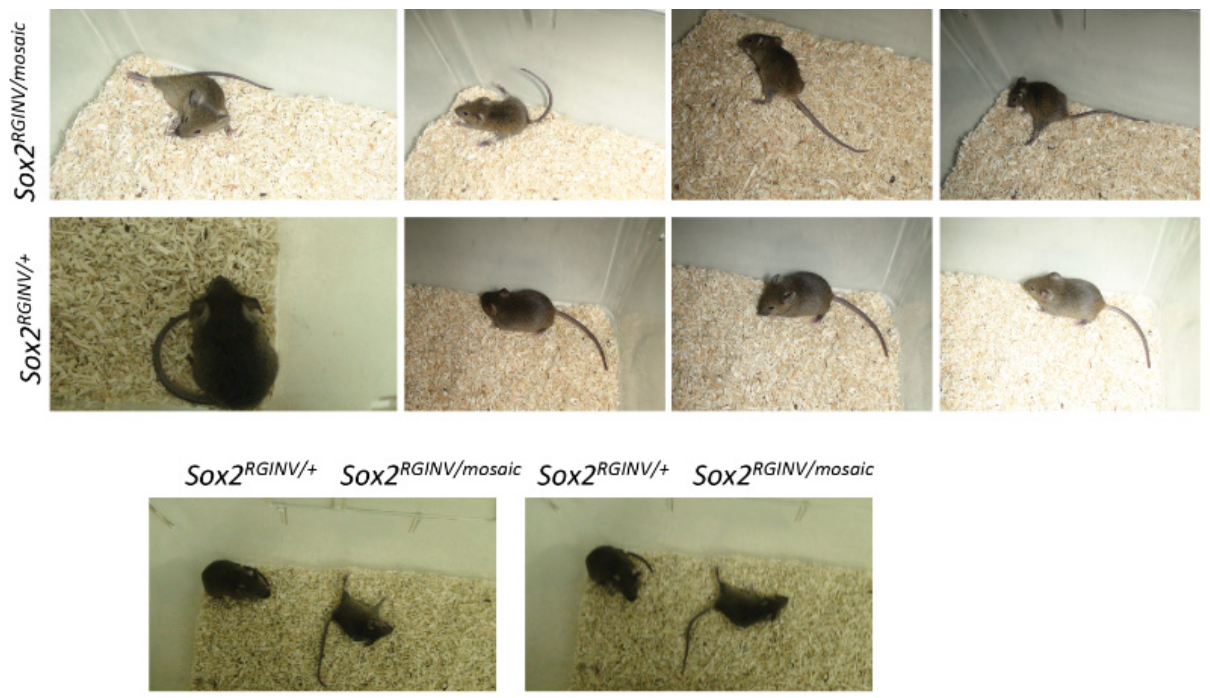

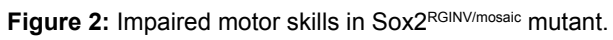

significantly reduced, especially the cerebellar vermis (Figure $1(\mathrm{C})$ ). On the assumption that the role of the cerebellum is to memorize information relating to neuromuscular actions we further studied the pathoanatomical structure of the cerebellar vermis, by performing sagittal cryosectioning of the vermis in its midline (Figure $1(\mathrm{C})$ ), and stained with Hematoxylin and Eosin (H\&E). ${ }^{\prime+}$ littermates, Sox ${ }^{\text {RGINV/ }}$ mosaic mouse demonstrates marked shrinkage of the cerebellum (Figure $1(\mathrm{D}, \mathrm{E}))$ secondary to severe disruption of the number of the granule neurons (Figure $1(F, G)$ ). The internal granule cell layer is filled to capacity and beyond, precluding further successful migration of granule cell neurons from the external granule cell layer (Figure $1(\mathrm{~F}, \mathrm{G})$ ). Sections of the lateral cerebellar hemispheres, revealed a particularly expanded granular region of the cerebellum, as a demonstration of unsuccessful migration of external granule cell neurons and their progenitors, resulting in their accumulation within the molecular layer and subpial regions of the cerebellar folium (Figure 1 (H,I)). Purkinje cells appear to be present in normal numbers, but the layer is distorted by the excess numbers of internal granular neurons (Figure $1(\mathrm{H}, \mathrm{I})$ ). Cerebellar white matter seems to be present in normal abundance, also hosting a relatively small number of granular neurons (Figure $1(\mathrm{H})$ ). Additionally, by focusing at the sulcal depths, we detected apparently normal numbers of Purkinje cells in somewhat better preserved layering (Figure $1(\mathrm{I})$ ).

\section{Discussion}

The cerebellar cortex is divided in the granule cell layer (innermost layer), the Purkinjje cell layer (middle layer) and the molecular layer (granule cells' axons and Purkinjie cells' dendrites). Cerebellar granule cells are small densely packed neurons, representing the highest number of neurons in the cerebellum and account for more than half of the neurons of the entire brain [19]. Sox 2 gene has recently been reported outside of established Neural Stem Cells (NSCs) niches, such as the Purkinje cell layer of the adult cerebellum [20].

Neural development and neurogenesis is governed by the temporal pattering and differentiation of early embryonic precursors of neuroectoderm. Segmentation of the hindbrain that is initiated around E8.5 of mouse embryonic development sets the boundaries of cerebellar formation. The rhombic lip that appears later at E10.5, plays a crucial role for the separation of GABAergic and glutamatergic neuronal progenitors, both of which underlie the formation of Purkinje and granule cells.

The present case study reveals for the first time that the prolonged cerebellar tangential, followed by radial, migration of the referred neuronal cell types, whose allocation continues even in the early postnatal stage, depends on Sox2 [13]. These results suggest that Sox2 loss of function in radial glial cells can generate neurological defects in cognitive behaviour, as a result of overproduction of immature/non committed granule cell neuron progenitor cells in the adult cerebellum. Furthermore, this case study highlights the critical requirement of transcriptional activity of Sox 2 for the proper regionalization of granular neural progenitors, maturation and developmental migration.

Interestingly, our pathoanatomical analysis experiments could suggest that Sox 2 is associated with the gene regulatory network that is responsible for the correct spatiotemporal allocation of granule cell precursors. This regulatory network includes a significant number of kinases and neurotrophins and theirs receptors with the most important to include Brain Derived Neurotrophic Factor (BDNG), Tyrosine Receptor Kinase B (TrkB), Calcium Dependent Secretion Activator 2 (CAPS2/CADPS2), neurotrophin 3, cAMP response element-binding (CREB) protein, Calcium/Calmodulin-dependent protein kinase type IV, Calcium/Calmodulin Dependent Protein Kinase Kinase 2, C-X-C Motif Chemokine Ligand 12, semaphoring 6a, Plexin A2 genes as reviewed by [21]. Further molecular analysis on Sox ${ }^{\text {RGINV/mosaic }}$ embryonic cerebellum would reveal the genetic regulatory partnerships that could potentially regulate the spatiotemporal tangential and radial migration of granule cell neuron progenitor cells, a process that extends from early embryogenesis till early adulthood.

\section{Materials and Methods}

\section{Experimental animals}

Mice were described elsewhere [7,14,16]. All animals were handled in strict accordance with good animal practice as defined by the Animals Act 160/03.05.1991 applicable in Greece, revised according to the $86 / 609 / \mathrm{EEC} / 24.11 .1986 \mathrm{EU}$ directive regarding the proper care and use of laboratory animals and in accordance to the Hellenic 
Citation: Mandalos NP, Karampelas I, Saridaki M, McKay RDG, Cohen ML, et al. (2018) A Role for Sox2 in the Adult Cerebellum. Stem Cell Res Ther 8: 433. doi: 10.4172/2157-7633.1000433

Page 4 of 4

License for Animal Experimentation at the BSRC "Alexander Fleming” (Prot. No. 767/28.02.07) issued after protocol approval by the Animal Research Committee of the BSRC “Alexander Fleming” (Prot. No. 3739/9.6.2016).

\section{Genotyping}

Tail, yolk sack or embryonic tissues were isolated and processed according to previously described methodology. PCR amplification conditions and primers used are described elsewhere [7,14,16].

\section{Embryo processing and histological analysis}

The mice were perfused intracardially with $4 \%$ PFA fixative in $0.1 \mathrm{M}$ Phosphate Buffer (PB, pH 7.4) using a 27 gauge needle under anaesthesia (Avertin/Tribromoethanol injection at the peritoneal cavity). For histological analysis, embryos were fixed with $10 \%$ Formalin for 24 hours at room temperature and then washed several times with PBS, placed in embedding cassettes and sectioned in a Leica RM2125RT microtome. Paraffin sections $(10 \mu \mathrm{m})$ were stained with Hematoxylin and Eosin and mounted with xylene based mounting medium, according to standard procedures [7].

\section{References}

1. Sillitoe RV, Marzban H, Larouche M, Zahedi S, Affanni J, et al. (2005) Conservation of the architecture of the anterior lobe vermis of the cerebellum across mammalian species. Prog Brain Res 148: 283-297. [PubMed]

2. Stoodley CJ, Limperopoulos C (2016) Structure-function relationships in the developing cerebellum: Evidence from early-life cerebellar injury and neurodevelopmental disorders. Semin Fetal Neonatal Med 21: 356-364. [PubMed]

3. Chi CL, Martinez S, Wurst W, Martin GR (2003) The isthmic organizer signal FGF8 is required for cell survival in the prospective midbrain and cerebellum. Development 130: 2633-2644. [PubMed]

4. Frantz GD, Weimann JM, Levin ME, Mcconnell SK (1994) Otx1 and Otx2 define layers and regions in developing cerebral cortex and cerebellum. J Neurosci 14: 5725-5740. [PubMed]

5. Di Giovannantonio LG, Di Salvio M, Omodei D, Prakash N, Wurst W, et al. (2014) Otx2 cell-autonomously determines dorsal mesencephalon versus cerebellum fate independently of isthmic organizing activity. Development 141: 377-388. [PubMed]

6. Gavalas A, Davenne M, Lumsden A, Chambon P, Rijli FM (1997) Role of Hoxa-
2 in axon pathfinding and rostral hindbrain patterning. Development 124: 36933702. [PubMed]

7. Mandalos N, Saridaki M, Harper JL, Kotsoni A, Yang P, et al. (2012) Application of a novel strategy of engineering conditional alleles to a single exon gene, Sox2. PLoS One 7: e45768. [PubMed]

8. Li H, Jin G, Qin J, Tian M, Shi J, et al. (2011) Characterization and identification of Sox2+ radial glia cells derived from rat embryonic cerebral cortex. Histochem Cell Biol 136: 515-526. [PubMed]

9. Pevny LH, Nicolis SK (2010) Sox2 roles in neural stem cells. Int J Biochem Cell Biol 42: 421-424. [PubMed]

10. Remboutsika E, Elkouris M, Iulianella A, Andoniadou CL, Poulou M, et al. (2011) Flexibility of neural stem cells. Front Physiol 2: 16. [PubMed]

11. Sild M, Ruthazer ES (2011) Radial glia: progenitor, pathway, and partner Neuroscientist 17: 288-302. [PubMed]

12. Alcock J, Lowe J, England T, Bath P, Sottile V (2009) Expression of Sox1, Sox2 and Sox9 is maintained in adult human cerebellar cortex. Neurosci Lett 450 : 114-116. [PubMed]

13. Ahlfeld J, Filser S, Schmidt F, Wefers AK, Merk DJ, et al. (2017) Neurogenesis from Sox2 expressing cells in the adult cerebellar cortex. Sci Rep 7: 6137.

14. Mandalos N, Rhinn M, Granchi Z, Karampelas I, Mitsiadis T, et al. (2014) Sox2 acts as a rheostat of epithelial to mesenchymal transition during neural crest development. Front Physiol 5: 345. [PubMed]

15. Mandalos NP, Remboutsika E (2017) Sox2: To crest or not to crest? Semin Cell Dev Biol 63: 43-49. [PubMed]

16. Poulou M, Mandalos NP, Karnavas T, Saridaki M, Mckay RD, et al. (2016) A "Hit and Run" Approach to Inducible Direct Reprogramming of Astrocytes to Neural Stem Cells. Front Physiol 7: 127. [PubMed]

17. Zhang J, Dublin P, Griemsmann S, Klein A, Brehm R, et al. (2013) Germline recombination activity of the widely used hGFAP-Cre and nestin-Cre transgenes. PLoS One 8: e82818. [PubMed]

18. Steadman PE, Ellegood J, Szulc KU, Turnbull DH, Joyner AL, et al. (2014) Genetic effects on cerebellar structure across mouse models of autism using a magnetic resonance imaging atlas. Autism Res 7: 124-137. [PubMed]

19. Nahm M, Rousseau D, Greyson B (2017) Discrepancy between Cerebral Structure and Cognitive Functioning: A Review. J Nerv Ment Dis 205: 967-972. [PubMed]

20. Rex M, Church R, Tointon K, Ichihashi RM, Mokhtar S, et al. (1998) Granule cell development in the cerebellum is punctuated by changes in Sox gene expression. Brain Res Mol Brain Res 55: 28-34. [PubMed]

21. Chedotal A (2010) Should I stay or should I go? Becoming a granule cell. Trends Neurosci 33: 163-172. [PubMed] 